\title{
Flavonoids Isolated from the genus Ficus and Their Biological Activities
}

\author{
Yaxian Zhao, ${ }^{\ddagger, a, b}$ Jing Niu, ${ }^{\ddagger, a}$ Qinru Zhou, ${ }^{a, b}$ Yan Chen, ${ }^{a, b}$ Shiquan Gan, ${ }^{a, b}$ Xiangchun Shen, ${ }^{*, a, b}$ \\ and Nenling Zhang ${ }^{\star, a, b}$ \\ ${ }^{a}$ School of Pharmacy, Guizhou Medical University/Engineering Center of Efficient Utilization of Natural Medicinal \\ Resources, Guiyang, Guizhou 550025, China \\ ${ }^{b}$ High Educational Key Laboratory of Guizhou Province for Natural Medicinal Pharmacology and Drug \\ Druggability/Key Laboratory of Optimal Utilization of Natural Medicinal Resources,
} Guiyang, Guizhou 550025, China

Email: shenxiangchun@126.com (X. S.); nenlingzhang@foxmail.com (N. Z.)

${ }^{\ddagger}$ Y. Z. and J. N. contributed equally to this work.

\begin{abstract}
There are about 1000 species in the genus Ficus and many can be used for medicinal purpose. The medicinal plants of this genus mainly contain terpenoids, flavonoids, alkaloids, and coumarins. In this paper, we summarized flavonoids isolated from the genus Ficus and their pharmacological effects including anti-bacterial, anti-inflammatory, antitumor, antioxidant, antiviral, protective activities on the cardiovascular system and other activities.
\end{abstract}

Keywords Ficus plants, chemical constituents, flavonoids, biological activity

\section{Introduction}

There are about 1,000 species of Ficus plants in the Moraceae family worldwide, and about 120 species in China. The Flora of China records 98 species and 3 subspecies. ${ }^{[1]}$ Ficus plants are mainly distributed in tropical and subtropical regions. In China, they are mainly distributed in Guizhou, Yunnan, Fujian, Guangdong, Guangxi, and Hainan. ${ }^{[2]}$ Many species in the genus Ficus are used in folk medicine to treat pneumonia, vitiligo, diarrhea, tonsillitis, cough, rheumatic pain and promote lactation. ${ }^{[3]}$ The parts for medicinal use of the plants from this genus mainly include roots, leaves, stems, fruits, and flowers. In recent years, researchers have conducted systematic studies on Ficus plants and found that they have terpenoids, flavonoids, alkaloids and coumarins with diverse pharmacological activities. Herein, we summarize the flavonoids isolated from the genus, the details of their plant source and their biological activities.

\section{Flavonoids Isolated from the genus Ficus}

Up to now, many researchers have investigated on the chemical composition and pharmacological effects of the medicinal plants from this genus, which led to the isolation of various chemical constituents. There are about 151 flavonoids discovered and characterized from 15 Ficus species, including Ficus. simplicissima Lour., F. pumila, F. hirta, F. stenophylla, F. carical Linn., F. pandurata Hance., F. microcarpa, F. sarmentosa var., F. tsiangii, F. tikoua Bur., F. thonningii Blume., F. auriculata L., F. rugosa Miq, F. bengalensis Linn., and F. hispida Linn (Figure 1).

Li et al. isolated fourteen flavonoids (1-14). Zheng et al. isolated two flavones [acacetin (15), tricin (16)] and a flavanonol [3-acetyl-3,5,4-trihydroxy-7-methoxylflavone (17) from the roots of $F$. simplicissima Lour. ${ }^{[4-7]}$ From $F$. pumila, Wu et al. ${ }^{[8-11]}$ isolated seventeen flavonoids (18-34) and Wei et al. isolated flavonoids $35-37 .{ }^{[12]}$ Shao summarized thirty-two flavones (38-69). ${ }^{[13]}$ A new flavone 3-acetyl-3,5,4'-trihydroxy-7-methoxylflavone $(\mathbf{7 0})$ was isolated from the roots of $F$. hirta. ${ }^{[14]}$ From the leaves of $F$. stenophylla, four flavones $(\mathbf{7 1 - 7 4 )}$ and two flavanes $(75-76)$ were isolated. ${ }^{[15]}$ Two new flavones, namely caricaflavonol diester A (77), caricaflavonol diester B (78), and (79-82) were isolated from the fresh stem barks of $F$. carical Linn. ${ }^{[16,17]}$ Ramadan et al. isolated eight flavones $(83-89)$ from the leaves of $F$. pandurata Hance. ${ }^{[18,19]}$ Liu et al. isolated flavonoids (90-91), two flavones (92-93) and seven isoflavones (94-100) from $F$. microcarpat. Qi et al. isolated a new isoflavone (5,4'-hydroxy-2"-dimethypyrano (5",6",7,8)flavone 101). An isoflavone $\left(5,3^{\prime}, 4^{\prime}, 2\right.$-tertrahydroxy6-(3-methyl-3"-butenyl)-isoflavone 101) and four flavanes (102-105) were extracted from the stems and leaves of $F$. microcarpa and other Ficus plants. ${ }^{[20-25]}$ Chen et al. summarized six flavonoids (106-111) from the Ficus plants. ${ }^{[26]}$ Dihydroquercetin (112), flavanone 3',5',5,7-tetrahydroxylfavanone (113) and dihydrokaempferol (114) were isolated in $F$. sarmentosa var. Henryi, and chrysoeriol (115) was purified from $F$. tsiangii. ${ }^{[27,28]}$

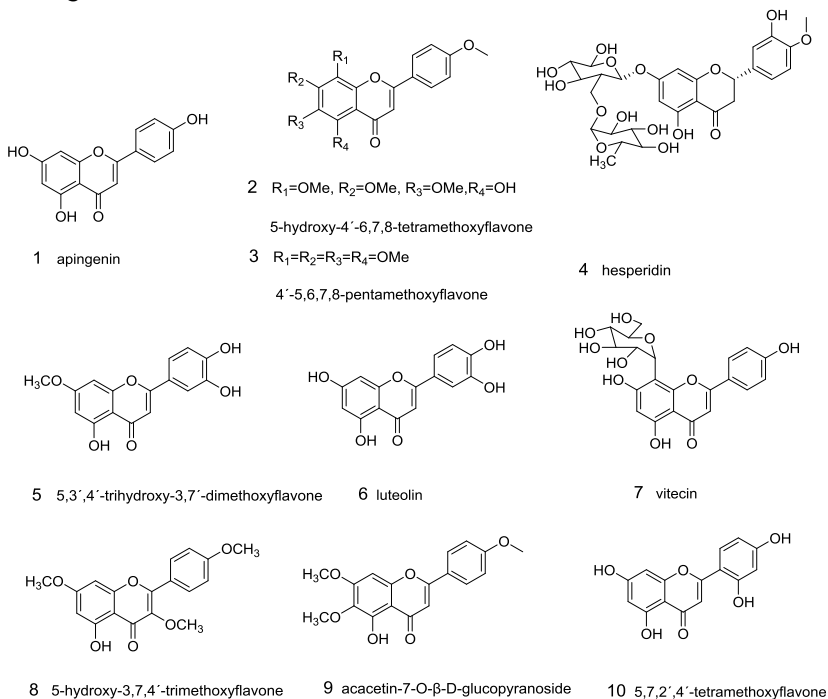




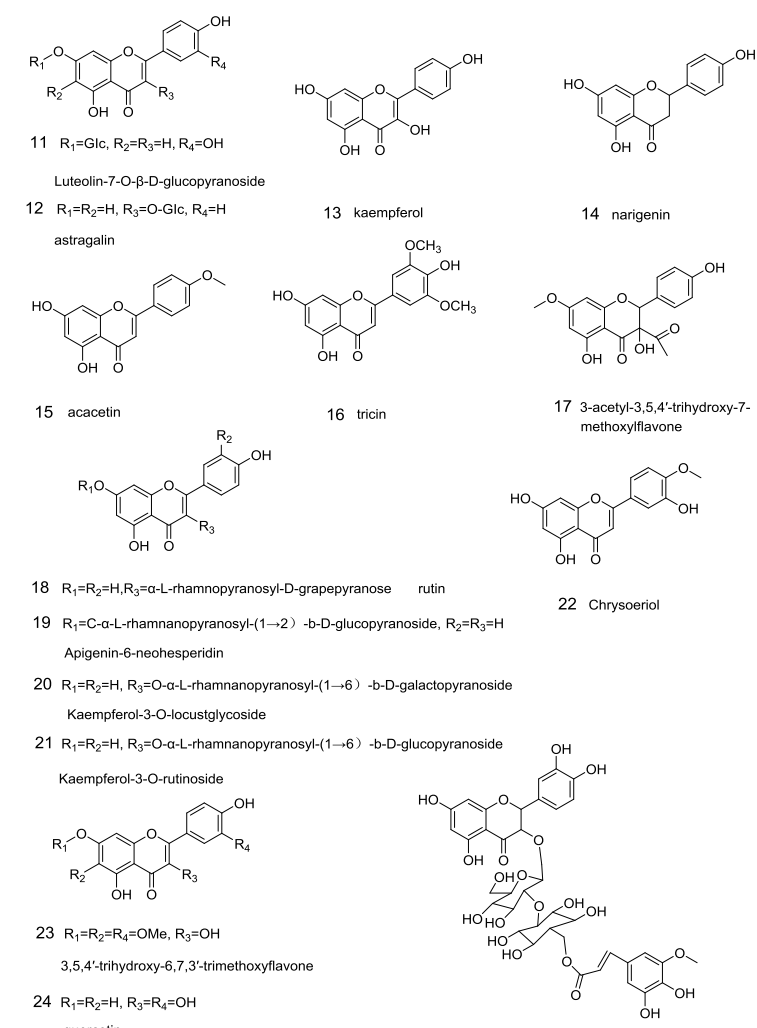

quercetin

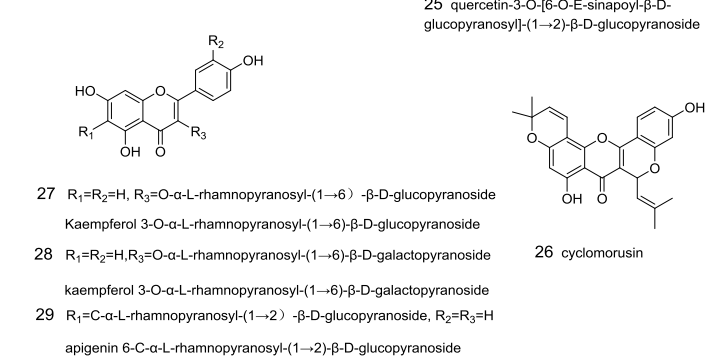

(n)

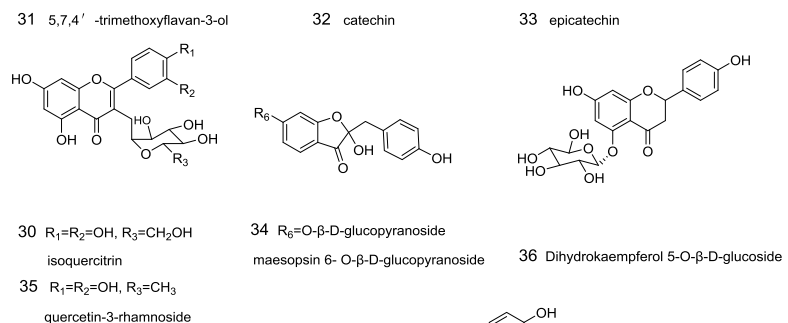

quecetin-3-rhamnoside

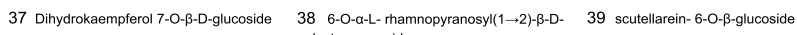

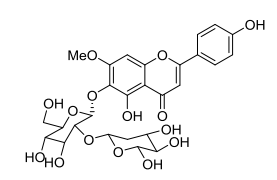

40 orbifolin-6-O-[a-L-arabinopyranosyl-(1 $\rightarrow 2)-\beta$ -

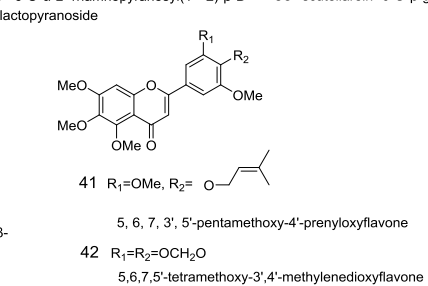

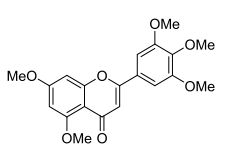

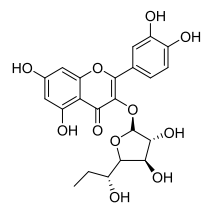

(1)

$43 \quad 5,7,3^{\prime}, 4^{\prime}, 5^{\prime}$-pentamethoxyflavone

44 isoquercitroside

45 chrysin<smiles>O=c1cc(-c2cc(O)c(O)cc2O)oc2cc(O)cc(O)c12</smiles>

47 scutellarein tetramethylether
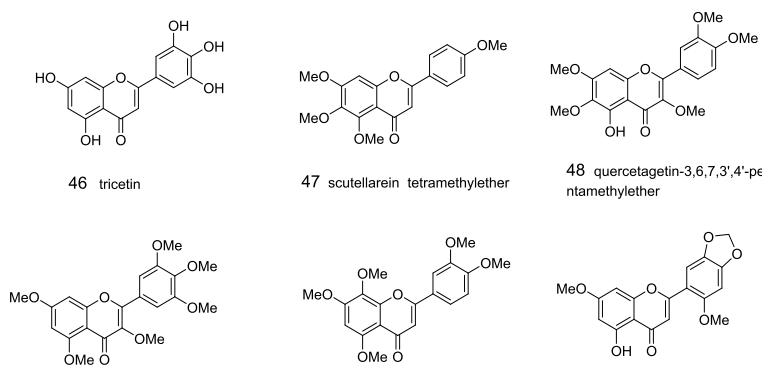

49 myricetin-hexamethylether

50 hypolaetin-pentamethylether

51 5-hydroxy-7, $5^{\prime}$-dimethoxy-3,4-

OMe

OMe

OMe

52 5-hydroxy-7,3,5'- trimethoxy-4'-(3,3-

53 5.6.73'.

525 -hydroxy-7, $33^{\prime}, 5^{\prime}-$
dimethylallyloxy) flavone

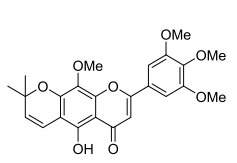

(1)

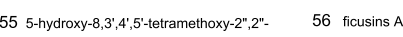

dimethylpyrano $\left(5^{\prime \prime}, 6: 6,6,7\right)$-flavone

(n)

58 ficuisoflavone

59 isolupinisoflavone $\mathrm{E}$

54 5-hydroxy-8, 3,',4'-trimethoxy-2", $2^{2-3}$ dimethylpyrano- $(5 ", 6 " 6,6,7)$-flavone

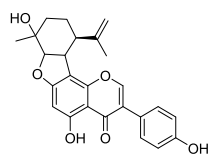

57 ficusins $B$
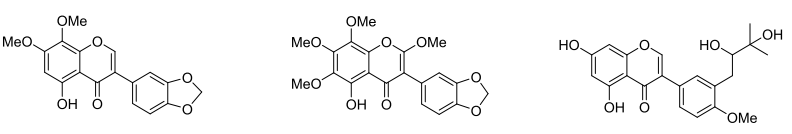

61 demethyl-meliternin

62 demethyl-melibentin

63 5,7-dihydroxy-4'-methoxy-3'-(2,3-

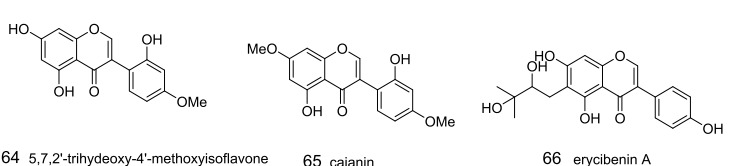

64 5,7,2'-trihydeoxy-4'-methoxyisoffavone $\quad 65$ cajanin

66 erycibenin A

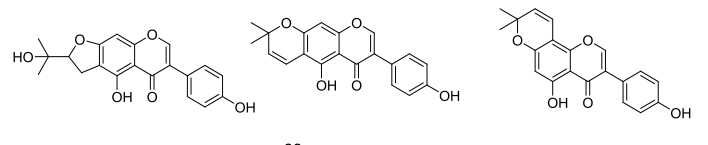

67 erythrinin C

69 derrone
(1)

70 3-acetyl-3,5,4-trihydroxy-7methoxylflavone<smiles>[R]C1Cc2c(O)cc(O)cc2OC1c1ccc(O)c(O)c1</smiles>

$75 \mathrm{R}=$ - $-\mathrm{OH} \quad(+)-$-catechin

$76 \mathrm{R}=\mathrm{a}-\mathrm{OH} \quad(-)-$ epicatechin

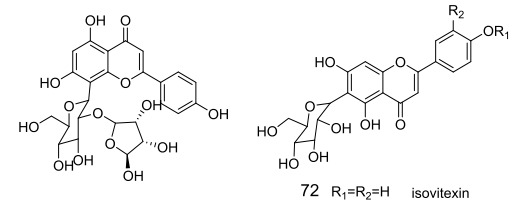

71 ficuflavoside

$73 \mathrm{R}_{1}=\mathrm{H}, \mathrm{R}_{2}=\mathrm{OH}$

luteolin-6-C-B-D-glucopyranoside

$74 \mathrm{R}_{1}=\mathrm{Glc}, \mathrm{R}_{2}=\mathrm{H}$ isosaponarin

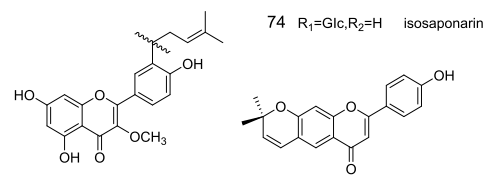
79 5.7,4'-trihydroxy-3-methoxy-3'-(met 80
hylbut-2-en-1-y)-avone 


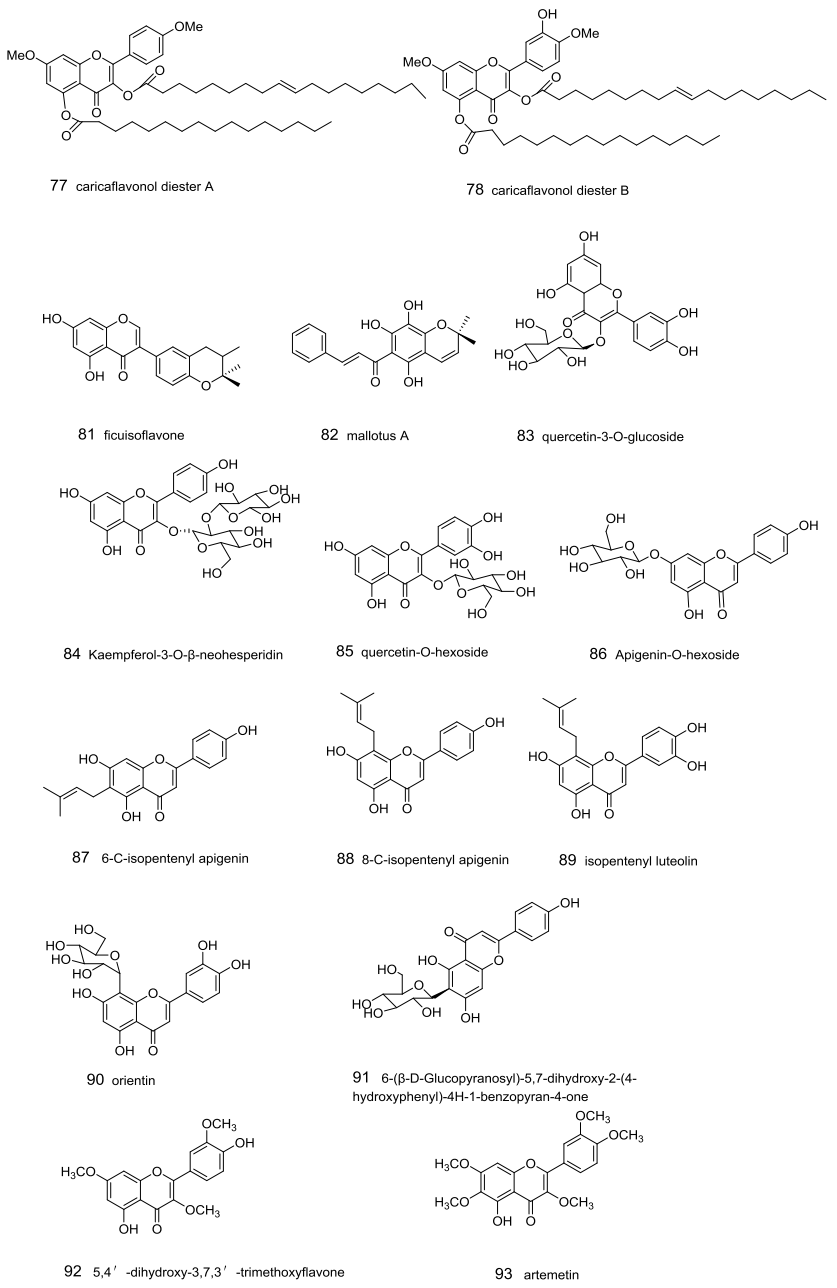

$$
\text { (icubee }
$$

114 thonningisoffavone

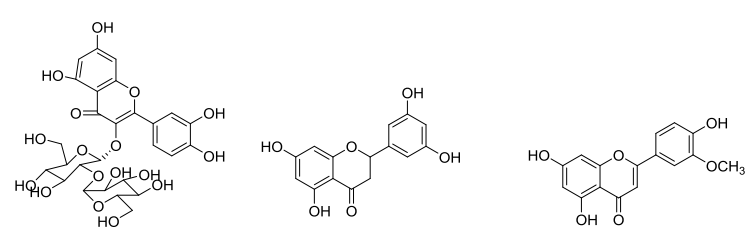

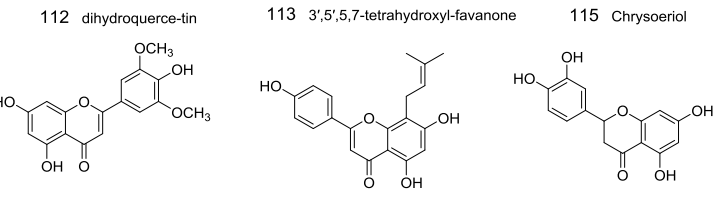

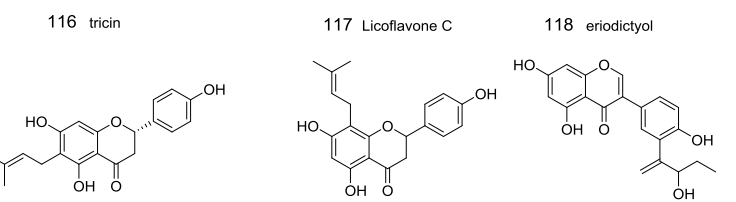

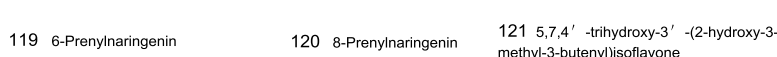

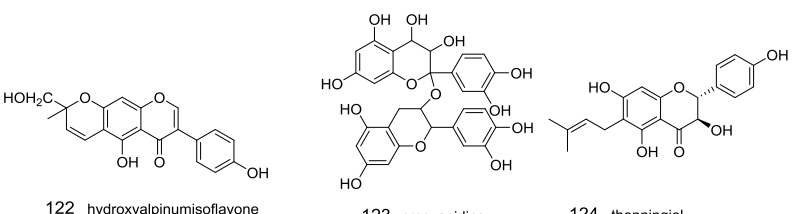

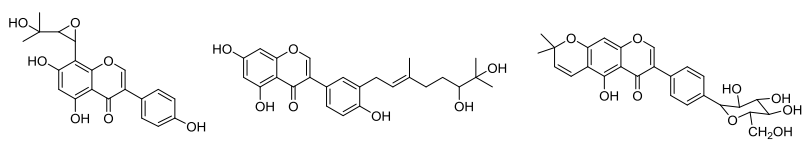
122 hydroxyalpinumisoflavon 123 procyanidins 124 thonningiol

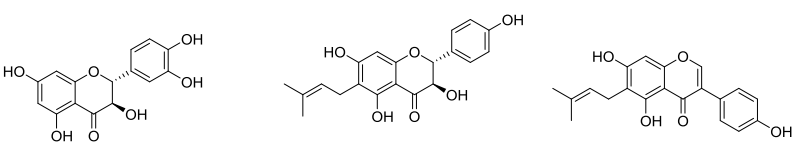

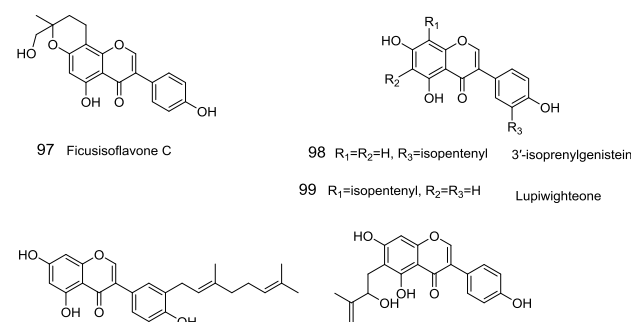

125 taxifolin

126 shuterin 127 wighteone

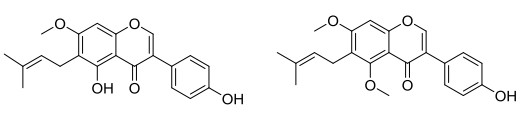

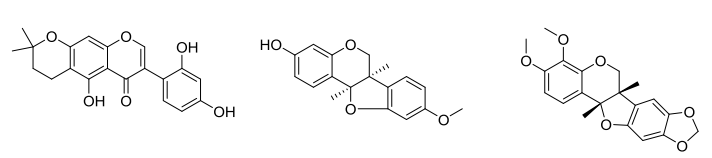

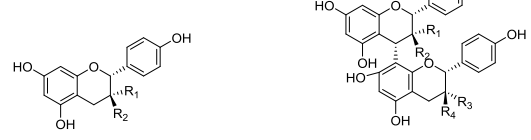

$102 R_{1}=H, R_{2}=\mathrm{OH} \quad(+)(2 R, 3 S)$ atzelechin $103 \mathrm{R}_{1}=\mathrm{OH}, \mathrm{R}_{2}=\mathrm{H}(-)(2 \mathrm{R}, 3 \mathrm{R})$ epiafzelechin

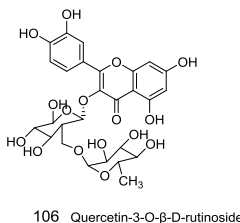

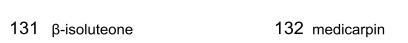

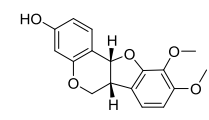

134 3-hydroxy-8,9-dimethoxy pterocarpan

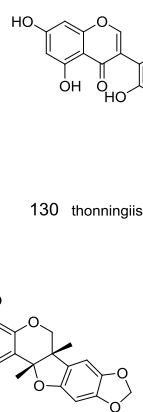

133 4-hydroxy- 3-methoxy-8,9-

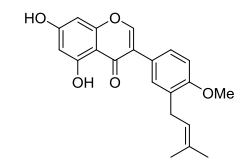

135 3'-(3-methylbut-2-enyl)biochanin $A$ 

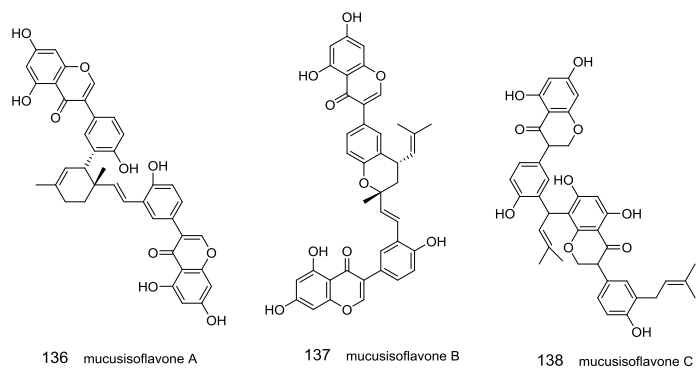

136 mucusisoflavone $\mathrm{A}$

137 mucusisoflavone B
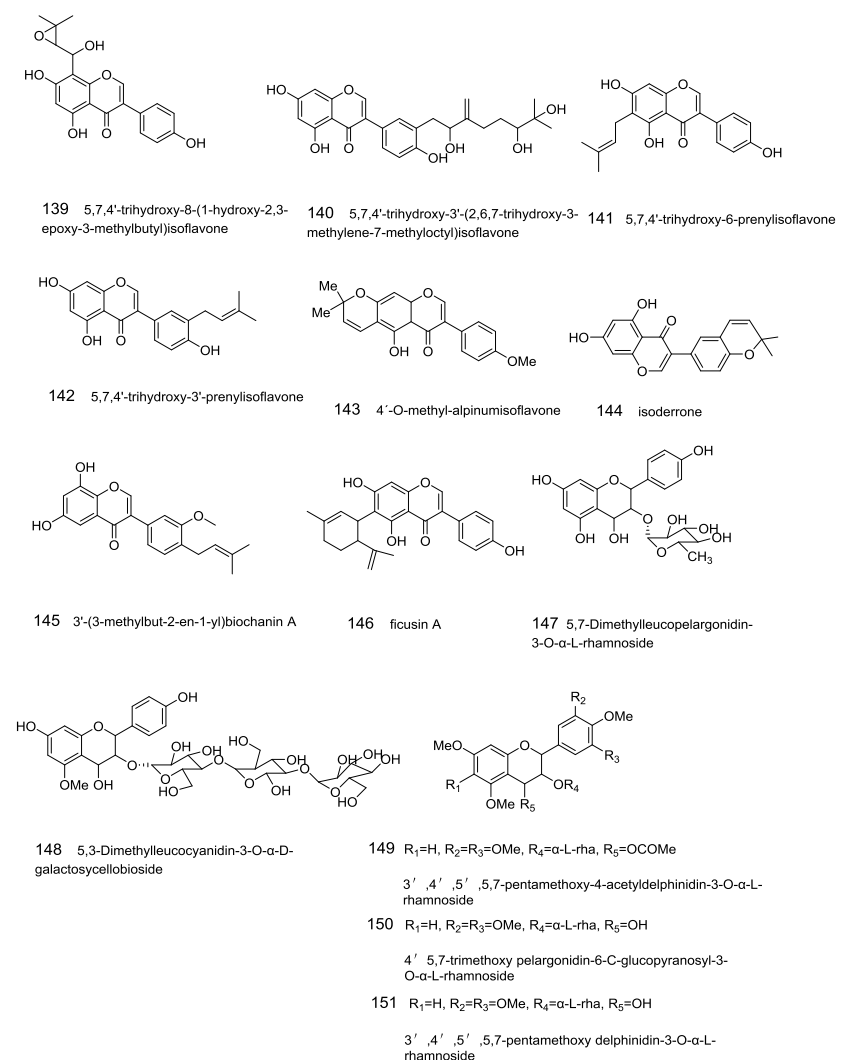

Figure 1 The structures of flavonoids from the ficus.

A new flavone, namely tricin (116), from the roots of $F$. stenophylla, was isolated by Zhang et al. ${ }^{[29]} \mathrm{Xu}$ et al. investigated on the rhizomes of $F$. tikoua Bur. and led to the isolation of licoflavone $C$ (117), eriodictyol (118), 6-prenylnaringenin (119), 8-prenylnaringenin (120), 5,7,4'-trihydroxy-3'(2-hydroxy-3-meth-yl-3-butenyl) isoflavone (121), hydroxyalpinumisoflavone (122), and procyanidin (123). ${ }^{[30-34]}$ Flavanonols (124-126) were isolated from $F$. thonningii Blume. by Yannick et al. ${ }^{[35]}$ Isoflavones $(\mathbf{1 2 7}-134)$ were extracted and isolated from $F$. carica ${ }^{[36]}$ From the figs of $F$. mucuso, Bankeu et al. isolated three isoflavones $(135-137) .^{[37]}$ Shao et al. purified 138-141 from the roots of $F$. macrocarpa ${ }^{[38]}$ and isolated 5,7,4'-trihydroxy-3'-prenylisoflavone (142), 4'-O-methylalpinumisoflavone (a novel isoflavone, 143) from the stems and roots of $F$. auriculata $L$. and $F$. tikoua Bur. ${ }^{[39,40]}$ Three isoflavones $(144-146)$ were obtained from F. hispida Linn. ${ }^{[41]}$ Flavanes (147-148) were obtained from the barks of $F$. bengalensis Linn. ${ }^{[42]}$ and flavanes $(149-151)$ were isolated from the stem barks of $F$. hispida Linn. ${ }^{[43]}$

\section{Bioactivities of Flavonoids from the genus Ficus}

Flavonoids isolated from the genus Ficus have antibacterial, anti-inflammatory, antitumor, antiviral and antioxidant activities. Meanwhile, other physiological activities such as free radical scavenging, and protective effect on the cardiovascular system have also been reported.

\section{Antibacterial activity}

The crude methanol extract of $F$. thonningii Blume. (Moraceae), and two flavanonols [taxifolin (125) and shuterin (126)] isolated from it showed moderate antibacterial activity against six microorganisms, with minimum inhibitory concentration (MIC) less than $1.5 \mathrm{mg} / \mathrm{mL}^{[35]}$ Zhang et al. studied the effect of apigenin (1) on methicillin-resistant Staphylococcus aureus (MRSA) strain and found apigenin showed potent resistance to MRSA strains and synergistic effect with quinolones and aminoglycoside antibiotics. ${ }^{[44]}$ Studies have shown that rutin (18) could affect the expression of SrtA while inhibiting the activity of SrtA, and it can significantly inhibit the agglutination reaction of Staphylococcus aureus by inhibiting the activity of SrtA. ${ }^{[45]}$ Chrysoeriol (115) showed good antibacterial activity with $\mathrm{IC}_{50}$ of $0.5 \mu \mathrm{M} \cdot{ }^{[46]}$ In addition, licoflavone C (117) was active against Pseudomonas aeruginosa and Escherichia coli $(7.81-15.62 \mu \mathrm{g} / \mathrm{mL})$ and showed important antifungal activity. ${ }^{[47]}$ Artemetin (93) showed strong antibacterial activity, the inhibitory concentration indices (FICls) with norfloxacin was $0.375 .{ }^{[48]}$ Gancaonin G (128) had certain antibacterial activity (with MIC of $1.56 \mu \mathrm{g} / \mathrm{mL}$ ). ${ }^{[9]}$ Ficuisoflavone (58) showed significant antibacterial activities against various terrestrial pathogenic bacteria such as salmonella and staphylococcus aureus with MIC values ranging from 1.30 to $39.93 \mu \mathrm{M} .{ }^{[50]}$ Catechin (32) had good antibacterial activity and inhibiting the growth of both Canidia Albicans and Trichophyton (with an Inhibition Zone-Diameter ranging between $4-8 \mathrm{~mm}$ and $7-14 \mathrm{~mm}$, respectively). ${ }^{[1]}$

\section{Anti-inflammatory activity}

Flavonoids exert anti-inflammatory and anti-immune activities by affecting mitosis, cell-cell interactions and cell secretion processes. ${ }^{[52]}$ Apigenin (1) could reduce neuroinflammation by restoring immune function. ${ }^{[4]}$ The research results showed that hesperidin (4) could inhibit the production of interleukin- 8 and tumor necrosis factor- $\alpha$ (tumor necrosis factor- $\alpha$, TNF- $\alpha$ ), and then inhibit the activation of NF-kB and phosphorylation of IK Ba and p38 mitogen-activated protein kinase. ${ }^{[53]}$ The antiinflammatory effect of luteolin $(6)$ is related to its inhibition of the release of inflammatory mediators and NF-kB-mediated gene expression. ${ }^{[54]}$ Vitecin (7) had an effect on acute and chronic inflammation. ${ }^{[5]}$ Astragalin (12) inhibits inflammation by down-regulating the NF-kB signaling pathway. ${ }^{[56]}$ Chrysoeriol (115) showed good anti-inflammatory effects and inhibited nuclear factor-kappa B (NF-KB) signaling. ${ }^{[57]}$ Kaempferol 3-O- $\alpha-L$-rhamnopyranosyl- $(1 \rightarrow 6)-\beta-D$ glucopyranoside (27) showed significant inhibitory effects on inflammatory mediators such as NO and PGE2, and anti-inflammatory activities in vitro with $106.5 \mathrm{pg} / \mathrm{mL}^{[58]}$ $5,7,3^{\prime}, 4^{\prime}, 5^{\prime}$-Pentamethoxyflavone (43) exerted the anti-inflammatory activity with an $\mathrm{IC}_{50}$ value of $53.40 \mu \mathrm{M} .^{[59]}$ Isovitexin (72) showed good antiinflammatory activities against Con A-activated T-lymphocytes and LPS activated RAW 264.7 macrophages. ${ }^{[6]}$ Orientin $(90)$ also showed a certain anti-inflammatory effect, and it effectively alleviated LPS-induced ALI by improving the histological changes of lung, decreasing the lung $W / D$ ratio and protein levels. ${ }^{[61]}$ The flavonoid tricin (116) was shown to improve the cutaneous system by regulating anti-inflammatory signaling pathways. ${ }^{[62]}$ In addition, taxifolin (125) showed a good anti-inflammatory effect and could inhibited HT22 cells apoptosis at concentration of $2.5 \mu \mathrm{m}\left(83 \%\right.$ cell survival). ${ }^{[63]}$ 


\section{Antitumor activity}

Flavonoids exert anti-tumor effects mainly by inducing tumor cell apoptosis, promoting tumor suppressor gene expression and anti-tumor cell proliferation, and interfering in tumor cell signal transduction. Hesperidin (4) could inhibit the signal cascade of phosphatidylinositol-3-kinase (PI3K/Akt) sirolimus receptor protein (mTOR) and glycogen synthase kinase $3 \beta$ (GSK-3ß) and cause tumor cells Apoptosis. ${ }^{[53]}$ Luteolin (6) had a significant inhibitory effect on solid tumors, ascites cancer and leukemia cells. It can also sensitize apoptosis-inducing factors and exert activities through multiple targets. ${ }^{[54]}$ Vitecin (7) could inhibit the proliferation of human cervical cancer HeLa cells and human ovarian cancer cells, with $I_{5}$ values as 28.2 and $36 \mathrm{mg} / \mathrm{L} .{ }^{[55]}$ Using a mouse xenograft model, astragalin (12) was found to inhibit tumor growth and induce cancer cell apoptosis in vitro. ${ }^{[56]}$ Isoquercitrin (30) showed notable inhibitory effects on tumor cell proliferation, though the mechanism is unknown. ${ }^{[64]}$ Scutellarein tetramethylether (47) had a certain inhibitory effect on colorectal cancer cells, and it could modulate markers of mesenchymal/metastatic transition. ${ }^{[65]} \quad 5,6,7,3^{\prime}, 4^{\prime}, 5^{\prime}-$ Hexamethoxyflavone (53) exerted good anticancer activity through arresting the cell cycle in the G2/M phase. ${ }^{[66]}$ In $\mathrm{H} 9 \mathrm{C} 2$ cells, kaempferol (13) dramatically reduced cispaltin-induced apoptosis and inflammatory response by modulating STING/NF-KB pathway. ${ }^{[67]}$ Thonningiol (124) is an effective cytotoxic phytochemical that could be explored to fight human carcinoma. ${ }^{[6]}$ Lupiwighteone (99) had anticancer effects against prostate cancer cells and neuroblastoma cells. ${ }^{[69]}$ Derrone (69) inhibited cell growth of various A549 cells, which was partially associated with cell apoptosis. ${ }^{[70]}$ Procyanidins (123) inhibited colorectal cancer cell growth through both redox and non-redox regulation of the epidermal growth factor signaling pathway. ${ }^{[71]}$

\section{Antioxidant activity}

It was found that apigenin (1) exerted antioxidant effects by directly scavenging free radicals, chelating metals, inhibiting NO production, DNA damage, and lipid peroxidation. ${ }^{[44]}$ Hesperidin (4) could reduce $\mathrm{Fe}^{2+}$, free radicals, hydrogen peroxide, peroxide and hydrogen by providing hydrogen to free radicals and forming a chelate between lipid free radicals and antioxidant free radicals. ${ }^{[53]}$ Astragalin (12) can be used as antioxidants in biological systems, especially for skin exposed to solar radiation, and protect cell membranes from active oxygen. ${ }^{[56]}$ Administration of rutin (18) also decreased thiobarbituric acid reactive substances and lipid hydroperoxides and increased the non-enzymic antioxidants significantly $(P<$ 0.05). ${ }^{[72]}$ Chrysoeriol (115), as an antioxidant, could increase the resistance of rice to the white-backed planthopper (WBPH). ${ }^{[57]}$ Kaempferol 3-O- $\alpha$ - $L$-rhamnopyranosyl- $(1 \rightarrow 6)-\beta-D$ galactopyranoside (28) showed antioxidant capacity. ${ }^{[7]}$ Chrysin (45), a natural flavonoid with potent antioxidant activity, showed protective activity against sodium arsenite (SA)-induced hepatotoxicity. ${ }^{[74]}$ Compound 71 exhibited potent antioxidant activities of $6.6-9.5 \mu \mathrm{M}$ Trolox equivalents at the concentration of $2.0 \mu \mathrm{M}^{[75]}$ Compounds cajanin (65), isovitexin (72), orientin (90), tricin (116) and eriodictyol (118) had antioxidant capacity. ${ }^{[76]}$ Thonningiisoflavone (130) and hydroxyalpinumisoflavone (122) showed efficient DPPH free radical scavenging activities with $\mathrm{IC}_{50}$ values of $65.50 \mathrm{M}$ and $68.20 \mathrm{M} \cdot{ }^{[36]}$ A series of flavonoid glycosides were isolated from the leaves of $F$. pumila and tested for their antioxidant activity. The results showed that rutin (18) could remove free DPPH. ${ }^{[56]}$ Isoquercitrin (30) and isoquercitroside (44) were also shown to have free radical scavenging activity, isoquercitrin exhibited antioxidant activity and UVB-induced generation of photoaging-related factor inhibition without showing any toxicity. ${ }^{[77,78]}$

\section{Antiviral activity}

$(+)(2 R, 3 S)$ Afcatechin (103) and (-) $(2 R, 3 R)$ epiafcatechin (104) were found effective against herpes simplex virus type 2 (HSV-2) cultured in rabbit kidney cells, the $\mathrm{IC}_{50}$ were 0.49 and $0.55 \mathrm{mg} / \mathrm{mL}$, the therapeutic index (TI) were 4.31 and 3.19 respectively, which can be used as an index component for the quality control of the medicinal materials of $F$. microphylla. ${ }^{[22]}$ Apigenin (1) had the effect of inhibiting EB virus. ${ }^{[44]}$ The study found that vitecin (7) had a significant inhibitory effect on Para3 with an $\mathrm{IC}_{50}$ of $20.8 \mathrm{mg} / \mathrm{L}^{[55]}$

\section{Activity on the cardiovascular system}

The flavonoids in Ficus can regulate the cardiovascular system by reducing the permeability of capillaries, lowering blood lipids, and lowering blood pressure. ${ }^{[79]}$ Apigenin (1) could improve the recovery function of the ischemic heart, reduce the area of myocardial infarction and the activity of creatine kinase isoenzyme. ${ }^{[4]}$ Hesperidin (4) could improve myocardial infarction area and edema by reducing oxidative stress and inflammation. ${ }^{[53]}$ Luteolin (6) could significantly reduce serum cholesterol (TC), triglyceride (TG), low-density lipoprotein cholesterol (LDL-C) and serum lipid peroxide (MDA) levels in hyperlipidemia rats, increase High-density lipoprotein cholesterol (HDL-C), and reduce arteriosclerosis index (Al). ${ }^{[54]}$ Orientin (91) had a dual role in the prevention and treatment of acute myocardial ischemia in rats. ${ }^{[61]}$

\section{Other activities}

5,7,4'-Trihydroxy-6-prenylisoflavones 5,7,4'-trihydroxy-3'-prenylisoflavones (142) were tested foranti-osteoporosis activity in vitro. The results showed that the two compounds have certain anti-osteoporous activity at 100 $\mu \mathrm{mol} / \mathrm{L}^{[39]} \mathrm{Fu}$ et al. evaluated the activity of inhibiting a-glucosidase of isolated compounds from the rhizomes of $F$. tikoua Bur. They found that alpinumisoflavone (68) and 4'-O-methyl-alpinumisoflavone (143) could inhibit a-glucosidase. ${ }^{[40]}$ Rutin (18) had a wide range of pharmacological effects, including anti-lipid peroxidation, and regulation of blood sugar and lipid metabolism disorders. ${ }^{[80]}$ 3'-(3-Methylbut-2-en-1-yl) biochanin A (145), isolated from the $F$. macrocarpa, showed an inhibitory effect against $\alpha$-glucosidase in vitro. ${ }^{[41]}$

\section{Main Structure and Activity Relationships of Flavonoids}

It has been found that the introduction of isoamyl groups at C-8 position of flavonoids and the methyl etherification of phenolic hydroxyl groups can further improve the activity of the flavonoids; the introduction of hydrophobic groups of different sizes (hydrogen, methyl, ethyl, methanol, etc.) at the C-3 position can maintain the high activity of the compounds; a hydrophobic group at position C-5 may be a pharmacodynamic group; the para-methoxy group in the $\mathrm{B}$ ring has a significant effect on the retention of activity and introduction of a methoxy group at position C-7 has strong antibacterial activity. ${ }^{[81]}$ In addition, a large number of studies have found that the phenolic hydroxyl group of flavonoids is the main active group for scavenging hydroxyl free radicals; the hydroxyl groups on the A ring and the $B$ ring are important active groups for scavenging free radicals, and the ortho-dihydroxyl group on the A ring and $B$ ring can significantly enhance the clearance effect. Besides, the hydroxyl group at the C-3', C-4' position can show a great clearance effect (the $B$ ring has a better effect than the $A$ ring). ${ }^{[82]}$

In addition, the structure-activity relationship study also found that by the replacement of isopentenyl groups to their 
skeleton, the fat solubility and affinity for biofilms of flavonoids would increase, thus, affect their biological activities. ${ }^{[3]}$

\section{Conclusions}

This article provides an overview of flavonoids from the genus Ficus and summarizes their pharmacological activities in detail. Researchers have investigated on the genus Ficus and up to date about 151 flavonoids, with some exhibiting various biological activities have been isolated. However, the chemical investigation mainly focuses on the species of $F$. pumila, $F$. auriculata Lour. and F. microcarpa L. In the years to come, in order to discover lead compounds from the genus, chemical constituents of other species in the genus need to be investigated more thoroughly and during the process new isolating methods are yet to be used more often. Moreover, the mechanism on the pharmacological activities of the active compounds needs to be elucidated more specific.

\section{Acknowledgement}

This work was supported by the National Natural Science Foundation of China (Nos. 81860612, 81703793), the Social Development Supportive Program of Science \& Technology Department of Guizhou Province (No. [2018]2767), the National Undergraduate Training Programs for Innovation and Entrepreneurship [No. S202010660013], the Science and Technology Innovation Advanced Individual of Guizhou Educational Department (No. QJHKY[2018]048), the Pharmacy International Scientific and Technological Cooperation Base of Guizhou Medical University (No. [2017]5802).

\section{Conflict of Interest}

The authors declare no conflict of interest.

Copyright (c) 2021 Yaxian Zhao, Jing Niu, Qinru Zhou, Yan Chen, Shiquan Gan, Xiangchun Shen, Nenling Zhang. This article is an open access article distributed under the terms and conditions of the Creative Commons Attribution (CC BY) license (http://creativecommons.org/ licenses/by/4.0/). The use, distribution or reproduction in other forums is permitted, provided the original author(s) or licensor are credited and that the original publication in this journal is cited, in accordance with accepted academic practice. No use, distribution or reproduction is permitted which does not comply with these terms.

\section{References}

[1] Editorial Committee of Chinese Flora of Chinese Academy of Sciences, Flora of China, Beijing, Science Press, 1998, Vol. 23, p. 66.

[2] Yan, C. C. Ph.D. Dissertation, Hainan University, Hainan, China, 2011.

[3] Fan, M. S.; Ye, G.; Huang, C. G. The advances of chemistry and pharmacological study of Ficus genus. Nat. Prod. Res. Dev. 2005, 17, 497-504.

[4] Li, C.; Bu, P. B.; Yue, D. K.; Sun, Y. F. Chemical constituents from roots of Ficus hirta. Chin. J. Chin. Mater. Med. 2006, 31, 131-133.

[5] Zhao, L. P.; Di, B.; Feng F. Chemical constituents from the roots of Ficus hirta. Pharm. Clin. Res. 2008, 16, 5-7.

[6] Jia, J.; Wang, Y.; Li, Y. L.; Ye, W. C. Study on the flavonoids and coumarins of Ficus simplicissima Lour. Chem. Ind. Forest Prod. 2008, 28, 52-55.

[7] Zheng, R. R.; Ji, J.; Wang, W. J.; Yang, H. B.; Zhang, Q. W. Study on the chemical constituents of Ficus simplicissima Lour. J. Chin. Med. Mater. 2013, 38, 3696-3701.

[8] Wu, W. M.; Hou, X. J.; Liu, L. M.; Tang, S. M.; Tong, L. F. Advance in chemical constituents and pharmacological activities of Ficus pumila. Chin. Med. J. Res. Prac. 2017, 31, 78-86.
[9] Luisa, P.; Elisabetta, E. C.; Ivano, M. Flavonoids from Ficus pumila. Biochem. Syst. Ecol. 2000, 28, 287-289.

[10] Zhang, F.; Zhang, J. Q.; Kong, L. Y. Research progress on chemical constituents of Ficus pumila. Chin. Tradit. Herbal. Drugs 2009, 40, 1554-1555.

[11] Fan, M.; S.; Ye, G.; Huang, C. G. Study on chemical constituents of Ficus pumila. Chin. Herb. Med. 2005, 36, 984-986.

[12] Wei, C. L.; Fan, G. Y. Chemical constituents from Ficus pumila. Chin. Herb. Med. 2014, 45, 615-621.

[13] Shao, T. M. Ph.D. Dissertation, Hainan Normal University, Hainan, China, 2013.

[14] Ya, L.; Zhang, X. Q.; Wang, Y.; Zhang, Q. W.; Chen, J. X.; Ye, W. C. Two new phenolic compounds from the roots of Ficus hirta. $J$. Nat. Prod. Res. 2010, 24, 621-625.

[15] Kiem, P. V.; Cuong, N. X.; Nhiem, N. X.; Thu, V. K.; Ban, N. K.; Minh, C. V.; Tai, B. H.; Hai, T. N.; Lee, S. H.; Jang, H. D.; Kim, Y. H. Antioxidant activity of a new C-glycosylflavone from the leaves of Ficus microcarpa. Bioorg. Med. Chem. Lett. 2011, 21, 633-637.

[16] Zaffer, B. M.; Mohd, A.; Rasool, S. New flavonol diesters from the stem bark of Ficus carical. Int. J. Clin. Pharm. Res. 2012, 3, 140-143.

[17] Zheng, F. S.; Chun, L.; Bang, W. Y. New Alkaloids and a-Glucosidase Inhibitory flavonoids from Ficus hispida. Chem. Mater. 2016, 4, 445-450.

[18] Ramadan, M. A.; Ahmad, A. S.; Nafady A M. Chemical composition of the stem bark and leaves of Ficus pandurata Hance. Nat. Prod. Res. 2009, 23, 1218-1230.

[19] Zhang, X. P.; Jiang, K. Z.; Lu, H. Q. Identification and characterization of major chemical compounds in the ethyl acetate extract from Ficus pandurata Hance. aerial roots by HPLC-Q-TOF MS. Chin. J. Mass Spectrom. Soc. 2015, 36, 310-320.

[20] Liu, M.; He, M. G.; Mei, Y.; Chen, X. Q.; Wang, J. H. Research progress in medicinal plant of Ficus microcarpa. Guangdong Agric. Sci. 2020, 47, 15-22.

[21] Yang, S. B.; Zhang, R. Z.; Jiang, Z. Y. Chemical constituents from root of Ficus tikoua Bur. Chin. Tradit. Pat. Med. 2014, 36, 554-558.

[22] Qi, C. C.; Chen, W. H.; Chen, G. Y.; Song, X. P.; Han, C. R. Chemical constituents from roots of Ficus auriculata. Chin. Herb. Med. 2013, 22, 3127-3130.

[23] Qi, C. C.; Han, C. R.; Chen, W. H.; Wu, Z. Y.; Ran, X. cCS 9th National Symposium on Natural Organic Chemistry, Chinese Chemical Society, Shanghai, 2012, p. 89.

[24] Shao, T. M.; Song, X, P.; Chen, G. Y.; Han, C. R.; Li, X. B. CCS 11th National Symposium on Natural Organic Chemistry, Chinese Chemical Society, Shanghai, 2016, p. 270.

[25] Hu, Y. J.; Wu, X. P.; Liu, N.; Zhang, F. X.; Lu, Y. Y. Flavan components with anti-HSV activity in the leaves of Ficus microcarpa. Trop. Subtrop. Botany 2010, 18, 559-563.

[26] Chen, S. F.; Liu, Y. C.; Long, F. L. Advances in study on chemical constituents of Ficus genus. J. Yangling. Vocat. Tech. Coll. 2010, 9, 15-19.

[27] Wang, X. G.; Shen, L. T.; Zeng, Y. Y.; Tian, Y. Q.; Xu, H. H. Flavonoids in Ficus sarmentosa var. Chin. Herb. Med. 2010, 41, 526-529.

[28] Wang, Y. L.; Duan, S. L.; Zhang, Q. Q.; Cheng, W.; Liang, H. Chemical constituents from stems of Ficus tsiangii. Chin. Herb. Med. 2014, 45, 333-336.

[29] Zhang, X. Q.; Jiang, W. W.; Wang, Y.; Li, Y. L.; Ye, W. C. A new phenylpropionate in the root of Ficus stenophylla. Acta Pharmacol. Sin. 2008, 43, 281-283.

[30] Xu, Z. S.; Li, S. M.; Feng, G. X. Studies on Chemical Constituents from Stem of Ficus ischnopoda. Chin. J. Exp. Tradit. Med. Form. 2013, 19, 152-155.

[31] Zhang, W. P.; Zhang, X. P.; Liu, N.; Rao, G. X. A review on ethnic medicine Ficus tikoua Bur.. Mod. Chin. Med. 2016, 18, 531-534.

[32] Wei, S. P.; Lu, L. N.; Ji, Z. Q. Chemical constituents from Ficus 
tikoua. Chem. Nat. Compd. 2012, 48, 484-485.

[33] Fu, G. M.; Li, W. J.; Huang, X. Z.; Zhang, R. Z.; Tian, K.; Hou, S. Q; $\mathrm{Li}, \mathrm{Y}$. K. Antioxidant and alpha-glucosidase inhibitory activities of isoflavonoids from the rhizomes of Ficus tikoua Bur. Nat. Prod. Res. 2018, 32, 399-405.

[34] Xu, W.; Wang, P.; Li, S. Z. Study on the chemical constituents of the rhizomes of Ficus tikoua Bur. Nat. Prod. Res. Dev. 2011, 23, 270-272.

[35] Yannick, S. F.; Bankeu, J. J. K.; Ali, M. S. Flavonoids and other bioactive constituents from Ficus thonningii Blume. (Moraceae). Phytochem. Lett. 2015, 11,139-145.

[36] Shao, M. H.; Zhang, W. H.; Zhang, M. M.; Liu, Y. P.; Zhao, F.; Fu, Y. $\mathrm{H}$. Chemical constituents from fruits of Ficus carica. Chin. Tradit. Herbal. Drugs 2019, 50, 2425-2528.

[37] Bankeu, J. K.; Bankeu, R.; Khayala, B. N. Isoflavone dimers and other bioactive constituents from the figs of Ficus mucuso. J. Nat. Prod. 2011, 74, 1370-1378.

[38] Shao, T. M.; Li, X. B.; Qi, C. C.; Chen, G. Y. Chemical constituents of isoflavonoids from roots of Ficus auriculata. Chin. J. Org. Chem. 2018, 38, 710-714

[39] Shao, T. M.; Song, X. P.; Han, C. R.; Chen, G. Y.; Chen, W. H. Chemical constituents of the stems of Ficus auriculata Lour. J. Asian Nat. Prod. Res. 2013, 25, 624-627.

[40] Chiang, Y. M.; Kuo, Y. H. Novel triterpenoids from the aerial roots of Ficus auriculata Lour. Nat. Prod. Res. 2017, 34, 7656-7661.

[41] Gan, C. Y.; Zhu, W. F.; Su, S. Z.; Pang, B. A review on chemical constituents and pharmacological activities of Ficus hispida Linn. Strait. Pharm. China 2018, 30, 31-36.

[42] Susan, D. R.; Mathew, B. C.; Dev, K. S.; Augusti, K. T. Antioxidant effect of two flavonoids from the bark of Ficus bengalensis Linn in hyperlipidemic rats. Indian J. Exp. Biol. 1998, 36, 902-906.

[43] Ase, B. D.; Warjeet, S. Isolation and antimicrobial studies of the compounds isolated from the stem bark of Ficus hispida Linn. Asian J. Chem. 2008, 20, 6027-6032.

[44] Guo, S.; Zhang, W. X.; Yu, W. Research progress on the pharmacological effects of apigenin. Hubei Univ. Sci. Technol. 2016, 30, 273-276.

[45] Ghorbani, A. Mechanisms of antidiabetic effects of flavonoid rutin. Biochem. Pharmacol. 2017, 10, 305-312.

[46] Jang, Y. H.; Park, R. Y.; Kim, K. M. Antimicrobial activity of chrysoeriol 7 and chochlioquinone 9, white-backed planthopperresistant compounds, against rice pathogenic strains. J. Biol. Basel 2020, 9, 382

[47] Edziri, H.; Mastouri, M. H.; Mahjoub, M. A. Antibacterial, antifungal and cytotoxic activities of two flavonoids from Retama raetam flowers. Mol. Phys. 2012, 17, 7284-7293.

[48] Kim, J. Y.; Shim, S. H. Rotundifolia anti-atherosclerotic effects of fruits of and their isolated compounds via inhibition of human LDL and HDL oxidation. Biomol. Eng. 2019, 9, 727-744.

[49] He, J.; Chen, L.; David, H.; Shi, W. Y.; Lu, Q. Y. Antibacterial compounds from Glycyrrhiza uralensis. J. Nat. Prod. 2006, 69, 121-124.

[50] Qi, C. C.; Fu, Y. H.; Chen, W. H. A new isoflavone from the roots of Ficus auriculata. Nat. Prod. Res. 2018, 32, 43-47.

[51] Anthonia, A. A.; Angus, N. O.; Ugochukwu, M. O. Secondary metabolites of endophytic fungi from Newbouldia laevis and Cassia tora leaves: prospecting for new antimicrobial agents. Rec. Pat. Antiinfect Drug Discov. 2021, 12, 22.

[52] Zhang, B. B. Research on plant flavonoids. J. Vision. 2018, 8, $155-157$.

[53] Xie, Q.; Wang, Q.; Gao, S. Q. Advances on the biological activity and mechanism of hesperidin. Electron. J. Metab. Nutr. Cancer 2020, 7, 13-17.

[54] Han, W.; Xing, Y.; Kang, T. G. Research progress on the biological activity of luteolin. Yunnan J. Tradi. Chin. Med. 2010, 31, 60-62.

[55] Yan, J.; Zheng, M. D.; Cui, Y. H. Shandong Med. J. 2017, 57, 110-112.
[56] Nie, L.; Peng, L.; Li, Y. F.; Wang, Q. X. Research advances in the biological activities and mechanism of astragalin. Chin. J. Trop. Agr. 2020, 40, 64-70.

[57] Wu, J. Y.; Chen, Y. J.; Bai, L. Chrysoeriol ameliorates TPA-induced acute skin inflammation in mice and inhibits NF-KB and STAT3 pathways. Phytomedicine 2020, 68, 153173.

[58] Jiao, B.; Xu, C. T.; Li, Qi. Chemical constituents of camellia cumin flavonoids and their in vitro anti-inflammatory activities. Chin. J. Chem. 2019, 41, 89-95.

[59] Wu, J.; Liu, K.; Shi, X. H. The anti-inflammatory activity of several flavonoids isolated from Murraya paniculata on murine macrophage cell line and gastric epithelial cell (GES-1). Pharm. Biol. 2016, 54, 868-881.

[60] Qi, Z.; Fang, X.; Xie, Y.; Wang, L.; Zhao, Y.; Zhao, L. Bioassay-guided isolation of anti-inflammatory constituents from Celtis sinensis leaves. J. Food Biochem. 2021, 45, 13580-13591.

[61] Guo, H.; Xu, J. Pharmacological Effects of Orientin. Chin. J. Ethnomed. Ethnopharm. 2014, 10, 5-6.

[62] An, M.; Kim, H.; Moon, J. M.; Ko, H. S.; Clayton, P.; Lim, Y. H. Enzyme-treated Zizania iatifolia ethanol extract protects from UVA irradiation-induced wrinkle formation via inhibition of iysosome exocytosis and reactive oxygen species generation. Antioxidants Res. 2020, 9, 912

[63] Muramatsu, D.; Uchiyama, H.; Kida, H.; Iwai, A. In vitro anti-inflammatory and anti-lipid accumulation properties of taxifolin-rich extract from the Japanese larch, Larix kaempferiln. J. Heliyon. 2020, 6, 5505-5556.

[64] Shui, L.; Wang, W.; Xie, M.; Ye, B.; Li, X.; Liu, Y.; Zheng, M. Isoquercitrin induces apoptosis and autophagy in hepatocellular carcinoma cells via AMPK/mTOR/p70S6K signaling pathway. J. Aging (Albany NY), 2020, 12, 24318-24332.

[65] Pereira, C. V.; Duarte, M.; Silva, P, L. Polymethoxylated flavones target cancer stemness and improve the antiproliferative effect of 5 -fluorouracil in a 3D cell model of colorectal cancer. Nutr. J. 2019, 11, 326-336.

[66] Borah, N.; Gunawardana, S.; Torres, H. ; McDonnell, S.; Van Slambrouck, S. 5,6,7,3',4',5'-Hexamethoxyflavone inhibits growth of triple-negative breast cancer cells via suppression of MAPK and Akt signaling pathways and arresting cell cycle. Int. J. Oncol. 2017, 51, 1685-1693.

[67] Chen, S.; Ma, J.; Yang, L.; Teng, M.; Lai, Z. Q.; Chen, X.; He, J. Anti-glioblastoma activity of kaempferol via programmed cell death induction: involvement of autophagy and pyroptosis. Front Bioeng Biotech. 2020, 8, 614419-614429.

[68] Kuete, V.; Ngnintedo, D. Fotso, G. W.; Ngadjui, B. T.; Keumedjjo, F.; Yeboah, S. O.; Andrae-Marobela, K.; Sivas, H. Cytotoxicity of seputhecarpan $\mathrm{D}$, thonningiol and 12 other phytochemicals from African flora towards human carcinoma cells. BMC Complem. Altern. Med. 2018, 18, 36-48.

[69] Won, Y. S.; Seo, K. L. Lupiwighteone induces caspase-dependent and independent apoptosis on human breast cancer cells via inhibiting PI3K/Akt/mTOR pathway. Food Chem. 2020, 135, 110863.

[70] Kang, M. J.; Kim, S. Y.; Kwon, E. B.; Jo, Y. H.; Lee, M. K.; Lee, H. S.; Moon, D. O.; Kim, M. O. Derrone induces autophagic cell death through induction of ROS and ERK in A549 cells. Plos One. 2019 14, 218659-218674.

[71] Daveri, E.; Adamo, A. M.; Alfine, E.; Zhu, W.; Oteiza, P. I. Hexameric procyanidins inhibit colorectal cancer cell growth through both redox and non-redox regulation of the epidermal growth factor signaling pathway. Redox. Biol. 2021, 38, 101830-101841.

[72] Kamalakkannan, N.; Prince, P. S. Antihyperglycaemic and antioxidant effect of rutin, a polyphenolic flavonoid, in streptozotocin-induced diabetic wistar rats. Basic Clin. Pharmacol. Toxicol. 2006, 98, 97-103.

[73] Du, Q. Z.; Zhao, Y. H.; Li, Bo. The structure identification and 
antioxidant activity analysis of flavonoids from the flowers of Evergreen oilseed cane. J. Food Sci. 2011, 32, 111-115.

[74] Mendez, P. P.; Alday, E.; Valdez, J.; Hernandez, J.; Valencia, D.; Velazquez, C. Seasonality modulates the cellular antioxidant activity and antiproliferative effect of sonoran desert propolis. Antioxidants Basel. 2020, 9, 1294-1309.

[75] Phan, V. K.; Nguyen, X. C.; Nguyen, X. N. Antioxidant activity of a new C-glycosyl flavone from the leaves of Ficus microcarpa. Bioorg. Med. Chem. Lett. 2011, 21, 633-637.

[76] Tang, L.; Qin, Y.; Ling, K.; Wan, H. Eriodictyol inhibits the growth of CNE1 human nasopharyngeal cancer growth by targeting MEK/ERK signalling pathway, inducing cellular autophagy and inhibition of cell migration and invasion. J. BUON. 2020, 25, 2389-2394.

[77] Jin, Y.; Lu, Y.; Han, G. Z.; Sun, H. J.;Yu, H. S.; Jin, F. X. Comparative study on the anti-free radical activities of quercetin, isoquercetin and rutin. Chin. Tradit. Herbal. Drugs. 2007, 38, 408-412.

[78] Guo, Y. M. Ph.D. Dissertation, Dalian Medical University, Liaoning, China, 2011.
[79] Jiang, H. W.; Li, C. Y.; Zhao, C. J.; Ren, X. T. The chemical constituents, pharmacological effects and clinical application of figs. Heilongjiang Sci. J. 2019, 10, 12-15.

[80] Lin, J. Clinical pharmaceutical special of rutin. Chin. J. Clini. Pharmacol. 2009, 3, 256-263.

[81] Xu, L.; Sun, P. Ph.D. Dissertation, Jiangxi University of Traditional Chinese Medicine, Jiangxi, China, 2015.

[82] Geng, G. X.; Huang, Y. W.; Guo, F. J. The research progress of isopentenyl flavonoids in psoralen and their pharmacological effects. Nat. Prod. Res. Dev. 2013, 25, 1297-1301.

[83] Xu, M. J. Wu, B.; Ding, T.; Chu, J. H.; Li. C.Y.; Zhang, J.; Wu, T.; Wu, J.; Liu, S. J.; Liu, S. L. Simultaneous characterization of prenylated fla-vonoids and isoflavonoids in Psoralea corylifolia L. by liquid chromatography with diode-array detection and quadrupole time-of-flight mass spectrometry. Rapid Commun. Mass Spectrom. 2012, 26, 2343-2358.

Received March 20, 2021 Accepted May 5, 2021 